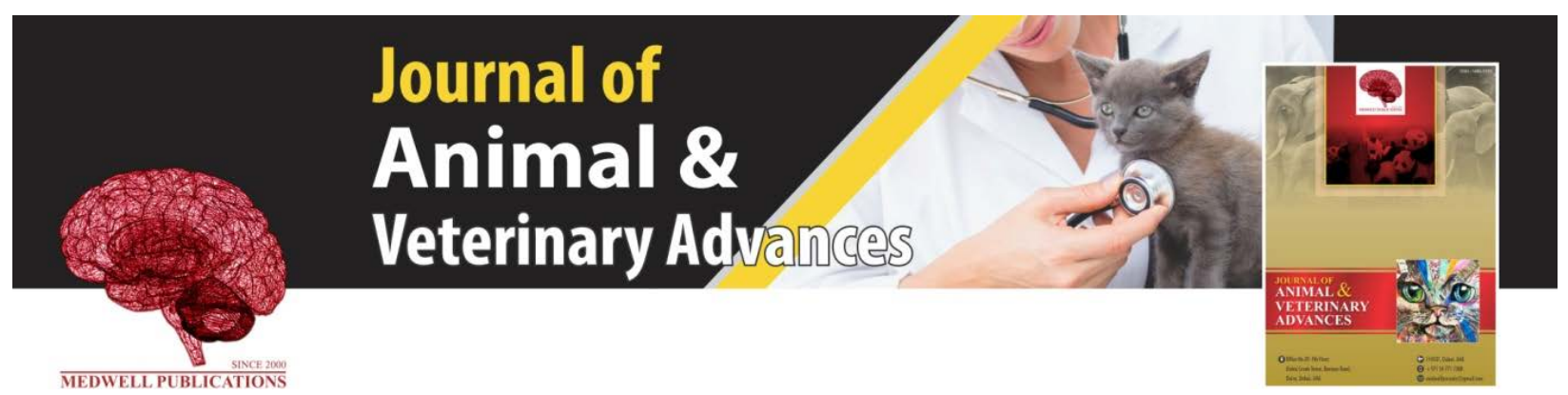

\title{
High Occurrence of Neospora caninum Antibodies in Buffaloes from the Central, Thailand
}

${ }^{1}$ Jitbanjong Toompong, ${ }^{2}$ Thuchadaporn Chaikhun-Marcou and ${ }^{3}$ Apiradee Intarapak

${ }^{1}$ Division of Parasitology, Department of Pre-Clinical Veterinary Science, Faculty of Veterinary Medicine, Mahanakorn,

${ }^{2}$ Obstetrics, Gynecology, Andrology and Artificial Insemination in Domestic Animals Clinic, Department of Clinical Veterinary Science, Faculty of Veterinary Medicine,

${ }^{3}$ Veterinary Public Health Clinic, Department of Clinical Veterinary Science, Faculty of Veterinary Medicine, Mahanakorn University of Technology, 140 Cheum-Sampan Rd., Nong Chok, 10530 Bangkok, Thailand

Key words: Neospora caninum, buffalo, seroprevalence, Thailand, Murah

Corresponding Author:

Jitbanjong Toompong

Division of Parasitology, Department of Pre-Clinical Veterinary Science, Faculty of Veterinary Medicine, Mahanakorn, Mahanakorn University of Technology, 140 Cheum-Sampan Rd., Nong Chok, 10530 Bangkok, Thailand

Page No.: 34-37

Volume: 19, Issue 3, 2020

ISSN: 1680-5593

Journal of Animal and Veterinary Advances

Copy Right: Medwell Publications
Abstract: Neospora caninum is now recognized as a major cause of abortion in cattle worldwide. The prevalence of $N$. caninum infection in buffaloes reported worldwide caused the buffalo considered to be an important intermediate host of $N$. caninum even though the role of $N$. caninum infection in buffalo is still unclear. At present, there was only few reports concerned $N$. caninum infection in buffaloes from Thailand. We examined the seroprevalence of $N$. caninum antibodies in 112 clinical healthy buffaloes from the central, Thailand using a commercial competitive ELISA (VMRD, Pullman, USA). Antibodies to $N$. caninum were found in 78 out of 112 buffaloes (69.6\%). Our study showed the high seroprevalence of $N$. caninum infection in buffaloes from Thailand. To our knowledge, this is the first report of $N$. caninum infection in Murah, river buffaloes and crossbred buffaloes in Thailand.

\section{INTRODUCTION}

Neospora caninum, an intracellular protozoa is recognized as an important cause of abortion and neonatal deathin cattle worldwide. In addition, it can also cause congenital disease in calves and milk yield reduction in the infected cows $^{[1]}$. The major route of $N$. caninum infection is transplacental transmission from infected cows to their off springs ${ }^{[2]}$. The buffaloes (Bubalus bubalis) are also an important natural host for $N$. caninum $^{[3,2]}$. Although, the role and consequence of $N$. caninum infection in buffaloes is still unclear but natural congenital infection of $N$. caninum in buffalo and successful isolation of the pathogen from buffalo tissues were reported ${ }^{[3-5]}$. In Thailand, $N$. caninum infection has been reported in dairy cattle and beef cattle; however, there is few information about $N$. caninum infection in buffaloes. Buffaloes in Thailand have been classified as swamp buffalo, river buffalo and crossbred. Traditionally, they were raised by small farm holders for multipurpose roles ascomplementary with their crop production and meator milk production.

We study the seroprevalence of $N$. caninum infection in buffaloes from large 4 herds in Nakorn Nayok and Chacheong-Sao province, the central part of Thailand. 


\section{MATERIALS AND METHODS}

Animals and serum samples: Serum samples were randomly collected by veterinary practitioners from 112 clinically healthy buffaloes originatedfrom four largest herdsof Nakorn Nayok province and Chacheong-Sao province in central Thailand from February to December in 2015. Serum samples were stored at $-20^{\circ} \mathrm{C}$ until being tested for the presence of antibodies against $N$. caninum. Ethical approval for the collection of the blood samples was obtained from the Institutional Animal Care and Use Committee, Mahanakorn University of Technology. Informed consent was obtained from the owners of those farms.

Serology: $N$. caninum specific IgG antibodies were detected by a commercial cELISA (VMRD, Pullman, USA) following the manufacturer's instructions. Briefly, the 96-well plates coated with $N$. caninum specific antigen provided in the kit were incubated with undiluted tested sera. The plates were washed and a conjugate was added. The plates were washed again and a chromogenic enzyme substrate was added. The Optical Density (OD) at $620 \mathrm{~nm}$ was read using a photometer (I\&S, Italy). The results were expressed as the percentage of inhibition. Sera were considered positive if the sample caused $\geq 30 \%$ inhibition, as indicated by the manufacturer.

Statistical analysis: The qualitative variables were described using frequencies and percentages. Comparison ofseroprevalence in different sexes, breed and age groups was performed by using Odd Ratio (OR) and 95\% CI of OR.

\section{RESULTS AND DISCUSSION}

N. caninum antibodies were detected in 78 (69.6\%) out of 112 buffalo samples. The proportions of seropositive animals by farm, sex, breed and age group were shown in Table 1.

$N$. caninum antibodies were detected in $100 \%(7 / 7)$ male buffaloes and $66.7 \%(52 / 78)$ female buffaloes. With regard to breed of the animals, the $N$. caninum antibodies were detected in $77.8 \%(21 / 27)$ of river buffaloes or Murah, 70\% (7/10) of swamp buffaloes, 58.5\% (24/41) of crossbred buffaloes while regard to age group, the $N$. caninum antibodies were detected in $70.3 \%$ (26/37) of animals younger than 3 year old and $65.0 \%$ (26/40) of animals older than 3 year old.

Buffalo is an importance source of meat and milk for human in Thailand. Nowaday, the role of $N$. caninum as a causal agent of abortion and economic loss in buffalo is still unclear. The abortion rate caused by $N$. caninum reported in buffalo at present was low which may caused by lower immune response in the placentomes of buffalo after getting $N$. caninum infection during geatation comparing to cattle ${ }^{[6]}$. Although, the abortion rate caused by $N$. caninum in buffalo was low but the seroprevalence of $N$. caninum infection in buffalo worldwide was three or four times higher than the seroprevalence in cattle ${ }^{[7]}$. Rezvan et al. ${ }^{[8]}$ indicated that the buffalo is more sensitive to $N$. caninum due to its life style which is different to cattle. On the other hand, some studies showed that the buffalo had lower $N$. caninum seroprevalence compared to cattle when reared in the same condition which resulted to the prospect that buffalo may be resistant to $N$. caninum infection $^{[9,10]}$.

The seroprevalence of $N$. caninum in buffaloes varies among countries and tests; for instance, $44 \%$ in Brazil by IFAT $^{[10]}, 68.5 \%$ in Romania by $\mathrm{PCR}^{[11]}, 88.3 \%$ in

Table 1: The occurrence of $N$. caninum antibodies by cELISA in buffaloes from the central Thailand

\begin{tabular}{lllll}
\hline Factor & Samples number & Positive number (\%) & OR & $95 \%$ CI of OR \\
\hline Farm & & & & \\
A & 28 & $22(78.6)$ & 2.64 & $0.83-8.65$ \\
B & 18 & $15(83.3)$ & 3.59 & $0.83-17.72$ \\
C & 11 & $9(81.8)$ & 3.23 & $0.56-24.04$ \\
D & 55 & $32(58.2)$ & 1 & - \\
Total & 112 & $78(69.6)$ & - & - \\
Sex & & & & - \\
Male & 7 & $7(100)$ & Undefined & - \\
Female & 78 & $52(66.7)$ & 1 & - \\
Total & 85 & $59(69.6)$ & - & $0.73-8.65$ \\
Breed & & & & \\
River buffaloes (Murah) & 27 & $21(77.8)$ & 2.48 & $0.3-9.55$ \\
Swamp buffaloes & 10 & $7(70)$ & 1.65 & - \\
Crossbred buffaloes & 41 & $24(58.5)$ & - & \\
Total & 78 & $52(66.7)$ & & - \\
Age group & & & 1.27 & - \\
$\leq 3$ years & 37 & $26(70.3)$ & - & \\
$>3$ years & 40 & $26(65.0)$ & & \\
Total77 & $52(67.5)$ & - & & \\
\hline
\end{tabular}


Australia by ELISA ${ }^{[12]}, 43.3 \%$ in Northeast of Argentina by IFAT ${ }^{[13]}, 25.4 \%$ in Northeast of Argentina by IFAT ${ }^{[14]}, 54.7 \%$ in Pakistan by ELISA ${ }^{[15]}, 37 \%$ in Iran by ELISA $^{[16]}, 55.5 \%$ in Brazil by ELISA ${ }^{[17]}, 24.3 \%$ in Mexico by ELISA ${ }^{[18]}$.

To our knowledge, there was few study concerned the infection of $N$. caninum in buffaloes from Thailand. This present study showed evidence for the first time that $N$. caninum infection in swamp buffaloes, river buffaloes and crossbred buffaloesin central part of Thailand is a highly endemic which was higher than the previous studies conducted in the northeast part. Nam et al. ${ }^{[9]}$ found that $6.4 \%$ of 532 swamp buffaloes in the Northeast of Thailand had N. caninum antibodies while $43.6 \%$ of 78 beef cattle from the same area were seropositive to $N$. caninum. Kengradomkij et al. ${ }^{[19]}$ showed that $9.1 \%$ of 628 water buffaloes in the northeast of Thailand were seropositive to $N$. caninum.

Although, our study showed that there was no association between the seropositive and the sex, the breed, the farm and the age group of buffalo but many studies showed that the seropositive for $N$. caninum infection in buffalo increased with age as in cattle and suggested that horizontal transmission from dogs was an important route of exposure to $N$. caninum $^{[3,15,20 \text {, }}$ $13,19,18,11]$. However, there were many studies showed that transplacental transmission can also occur in buffaloes as in cattle ${ }^{[21,4,14,5,22,23]}$. The major route of $N$. caninum transmission in buffaloes should be more investigated.

\section{CONCLUSION}

According to the result of the present study, the high prevalence of $N$. caninum infection in buffaloes in this area from Thailand suggested that further study on the influence of this agent in buffaloes as the intermediate host of $N$. caninum are needed and the management and control strategies should be determined.

\section{ACKNOWLEDGEMENT}

This research was financially supported by Mahanakorn University of Technology.

\section{REFERENCES}

01. Anderson, M.L., A.G. Andrianarivo and P.A. Conrad, 2000. Neosporosis in cattle. Anim. Reprod. Sci., 60: 417-431.

02. Dubey, J.P., 2003. Review of Neospora caninum and neosporosis in animals. Korean J. Parasitol., 41: 1-16.

03. Rodrigues, A.A.R., S.M. Gennari, D.M. Aguiar, C. Sreekumar and D.E. Hill et al., 2004. Shedding of Neospora caninum oocysts by dogs fed tissues from naturally infected water buffaloes (Bubalus bubalis) from Brazil. Vet. Parasitol., 124: 139-150.
04. Chryssafidis, A.L., R.M. Soares, A.A. Rodrigues, N.A. Carvalho and S.M. Gennari, 2011. Evidence of congenital transmission of Neospora caninum in naturally infected water buffalo (Bubalus bubalis) fetus from Brazil. Parasitol. Res., 108: 741-743.

05. Auriemma, C., M.G. Lucibelli, G. Borriello, E. Carlo and A. Martucciello et al., 2014. PCR detection of Neospora caninum in water buffalo foetal tissues. Acta Parasitologica, 59: 1-4.

06. Canton, G.J., J.L. Konrad, D.P. Moore, S.G. Caspe, J. Palarea-Albaladejo, C.M. Campero and F. Chianini, 2014. Characterization of immune cell infiltration in the placentome of water buffaloes (Bubalus bubalis) infected with Neospora caninum during pregnancy. J. Comp. Pathol., 150: 463-468.

07. Reichel, M.P., M.M. McAllister, A. Nasir and D.P. Moore, 2015. A review of Neospora caninum in water buffalo (Bubalus bubalis). Vet. Parasitol., 212: 75-79.

08. Rezvan, H., A. Khaki, M. Namavari and R. Abedizadeh, 2019. An investigation of the concurrency of anti-Neospora antibody and parasitemia in water buffalo (Bubalus bubalis) in Northwest of Iran. Vet. Res. Forum, 10: 79-84.

09. Nam, N.H., A. Chanlun, K. Kanistanon and S. Aiumlamai, 2012. Seroprevalence of Neospora caninum in swamp buffaloes and beef cattle in the North-East of Thailand. Thai J. Vet. Med., 42: 213-218.

10. Da Silva, J.B., R.R. Nicolino, G.M. Fagundes, H. Dos Anjos Bomjardim and A.D.S.B. Reis et al., 2017. Serological survey of Neospora caninum and Toxoplasma gondii in cattle (Bos indicus) and water buffaloes (Bubalus bubalis) in ten provinces of Brazil. Comp. Immunol. Microbiol. Infectious Dis., 52: 30-35.

11. Barburas, D., A. Gyorke, A.M. Ionica, R. Barburas, V. Mircean and V. Cozma, 2019. Evidence of Neospora caninum infection in buffaloes (Bubalus bubalis) from Northwestern Romania. Parasitol. Res., 118: 1667-1671.

12. Neverauskas, C.E., A. Nasir and M.P. Reichel, 2015. Prevalence and distribution of Neospora caninum in water buffalo (Bubalus bubalis) and cattle in the Northern Territory of Australia. Parasitol. Int., 64: 392-396.

13. Moore, D.P., J.L. Konrad, S. San Martino, M.P. Reichel and D.B. Cano et al., 2014. Neospora caninum serostatus is affected by age and species variables in cohabiting water buffaloes and beef cattle. Vet. Parasitol., 203: 259-263. 
14. Konrad, J.L., L.M. Campero, G.S. Caspe, B. Brihuega and G. Draghi et al., 2013. Detection of antibodies against Brucella abortus, Leptospira spp. and Apicomplexa protozoa in water buffaloes in the Northeast of Argentina. Trop. Anim. Health Prod., 45: 1751-1756.

15. Nasir, A., M. Ashraf, M.S. Khan, T. Yaqub, A. Javeed, M. Avais and F. Akhtar, 2011. Seroprevalence of Neospora caninum in dairy buffaloes in Lahore district, Pakistan. J. Parasitol., 97: 541-543.

16. Hajikolaei, M.R.H., S. Goraninejad, H. Hamidinejat, M. Ghorbanpour and R. Paryab, 2007. Occurrence of Neospora caninum antibodies in water buffaloes (Bubalus bulalis) from the South-Western region of Iran. Bull. Vet. Inst. Pulawy, 51: 233-235.

17. Da Silva, J.B., P.N. Dos Santos, G.N. De Santana Castro, A.H. Da Fonseca and J.D. Barbosa, 2014. Prevalence survey of selected bovine pathogens in water buffaloes in the North region of Brazil. J. Parasitol. Res., Vol. 2014, 10.1155/2014/603484

18. Romero-Salas, D., C. Alvarado-Esquivel, G. Dominguez-Aguilar, A. Cruz-Romero and N. Ibarra-Priego et al., 2017. Seroepidemiology of infection with Neospora caninum, Leptospira, and bovine herpesvirus type 1 in water buffaloes (Bubalus bubalis) in Veracruz, Mexico. Eur. J. Microbiol. Immunol., 7: 278-283.
19. Kengradomkij, C., T. Inpankaew, K. Kamyingkird, K. Wongpanit and S. Wongnakphet et al., 2015. Seroprevalence and risk factors associated with exposure of water buffalo (Bubalus bubalis) to Neospora caninum in Northeast Thailand. Vet. Parasitol., 207: 156-160.

20. Sengupta, P.P., M. Balumahendiran, A.G. Raghavendra, T.G. Honnappa, M.R. Gajendragad and K. Prabhudas, 2012. Prevalence of Neospora caninum antibodies in dairy cattle and water buffaloes and associated abortions in the plateau of Southern Peninsular India. Trop. Anim. Health Prod., 45: 205-210.

21. Rodrigues, A.A.R., S.M. Gennari, V.S.O. Paula, D.M. Aguiar and T.U. Fujii et al., 2005. Serological responses to Neospora caninum in experimentally and naturally infected water buffaloes (Bubalus bubalis). Vet. Parasitol., 129: 21-24.

22. Konrad, J.L., D.P. Moore, G. Crudeli, S.G. Caspe and D.B. Cano et al., 2012. Experimental inoculation of Neospora caninum in pregnant water buffalo. Vet. Parasitol., 187: 72-78.

23. Chryssafidis, A.L., G. Canton, F. Chianini, E.A. Innes, E.H. Madureira, R.M. Soares and S.M. Gennari, 2015. Abortion and foetal lesions induced by Neospora caninum in experimentally infected water buffalos (Bubalus bubalis). Parasitol. Res., 114: 193-199. 